\title{
Can citizen science complement official data sources that serve as evidence-base for policies and practice to improve water quality?
}

\author{
Ariane König, Karl Pickar, Jacek Stankiewicz* and Kristina Hondrila \\ University of Luxembourg, Esch-sur-Alzette, Luxembourg
}

\begin{abstract}
Addressing environmental issues in policy making requires recognising these issues as part of a complex socio-ecological system. The evidence base for such policies and associated monitoring and implementation measures, as well as related official indicators, statistics and environmental accounts are receiving increasing attention. This paper explores the potential of citizen science as a non-traditional source of data to complement the current data production process for evidence-based policy-making, using pollution of surface waters and its effect on associated ecosystems as an example. The paper develops a framework that helps to explore the official data production process in relation to different purposes of environmental policies. This highlights different challenges that the current official data production process sees itself confronted with in relation to the different purposes of the policies and associated monitoring regimes. These questions are explored with reference to the case of evidence-based policy making on water quality of surface freshwater in the EU, with a focus on Luxembourg. The analysis is based on extensive documentary analysis and literature review, as well as a series of interviews and participatory workshops with various stakeholders, and first results of a pilot project work with engaged citizen volunteers to solicit data on water quality with a focus on its nutrient content. On this basis, this paper argues that citizen science has the clear potential to meaningfully contribute both to the evidence base for policy and practice, as well as to an improved governance process.
\end{abstract}

Keywords: Citizen science, social-ecological systems, adaptive governance, monitoring, evidence-base, water quality

\section{Introduction}

Effectively addressing environmental issues in policy-making and in practice requires facing the complexity and uncertainty that are inherent in coupled human-environment systems [1,2]. The EU Green Deal draws increasing political and public attention to a range of environmental issues, such as water quality, biodiversity loss, and land degradation. Environmental governance in particular in these areas cannot be focused on single issues, but must consider complex human-environment interactions and interconnec-

* Corresponding author: Jacek Stankiewicz, University of Luxembourg, Esch-sur-Alzette, Luxembourg. jacek.stankiewicz@uni.lu. tions between global changes and their differing local repercussions [3]. This creates new challenges to achieving sustainable and equitable outcomes in socioecological systems [4]. Patterns of behavior in such systems emerge from interactions between diverse factors in the changing social sphere, ecosystems and technology. Accelerating and interconnected changes in the environment, society and technology that play out differently across diverse locations call for a shift in prevailing governance approaches from more traditional hierarchical modes that focus on environmental regulation and compliance to more distributed, networked and locally adaptable and responsive approaches $[5,6]$.

Changes in environmental governance towards more adaptive governance with distributed responsibilities 
and accountabilities has both procedural and substantive implications for policy-making and the associated evidence-base [4]. Procedurally, adaptive governance demands more participation in processes for developing policies and implementation measures. Moreover, as illustrated particularly well in the case of policies and laws on water quality, competing responsibilities and interests of various stakeholders often with conflicting perspectives render problem definition and the development of robust action pathways difficult. Stakeholders are often reluctant, or unable to, go beyond mere compliance with their requirements $[4,7]$.

Substantially, in terms of the scope and content of environmental policies and their the evidence base, there is a clear need to review contents to be able to consider prevailing patterns of behavior as outcomes of dynamic and complex social-ecological-technological systems; a greater diversity of factors than just environmental data are now considered salient for environmental governance. Furthermore, greater attention to changes in local factors affecting how we engage with the environment and regenerate water quality and biodiversity require data production approaches that allow aggregating and disaggregating data sets in a more flexible manner. Such data sets can then potentially be drawn upon in order to inform policies (EU and national) as well as local action. Salience, comprehension of and trust in the evidence base is required across levels of governance in multi-level governance systems. This warrants the consideration of engaging data users across all levels in the design and production of such data pools.

This paper highlights the need for reframing the contents and processes to produce the evidence base for environmental governance, and explores the potential of citizen science to complement the current official data production process. Towards this goal the paper first develops an analytic framework that helps to explore the new requirements for the evidence base and data production processes in view of a different understanding of the purpose of such an evidence base in relation to a shift to adaptive governance processes. The next section discusses the potential of citizen science to complement official production for the evidence base for environmental policies in general terms with reference to relevant academic literature. This question is then explored in more concrete terms by considering the case of water governance and in particular the evidence base for the implementation of the EU Water Framework Directive and related legislation. The potential of citizen science to complement traditionally produced official data is explored with reference to a related research project situated in Luxembourg. The conclusion and outlook consider requirements for developing citizen science, such that it can meaningfully complement official data to inform both policy making and local action. Merits, limitations, risks and opportunities and different roles of experts engaged in official data production processes and other stakeholders and citizen volunteers are critically discussed.

\section{Reconsidering the evidence base for environmental policies in view of the purposes of adaptive governance: An analytic framework and methods}

An approach suggested for the management of complex, dynamic socio-ecological systems is adaptive governance [8]. A fundamental assumption of this approach, also termed adaptive management, is that landscapes need to be understood and governed as complex social-ecological systems rather than as ecosystems alone. Adaptive governance studies have illuminated the intricate interplay of individual actors, organizations, and institutions that interact with societies to implement ecosystem management $[5,6]$. The involvement of all the relevant actors is a prerequisite to nimbly respond to accelerating and interconnected changes in the social, environmental and technological spheres.

Reliable data collection, assessment and evaluation are essential to successful adaptive governance. Environmental policies are important in management practices, but how they affect, or define, data collection is often not clear [4]. Individual actors are often unable to collect more data than is needed for the compliance with their legal requirements [7]. Bringing all actors in the system together within the flexible mechanism of adaptive governance challenges accountability [9] and builds system-wide awareness of ecological dynamics. Active engagement of a wide range of actors and stakeholders is also vital for successful system management. For this all available data not only need to be publicly available, but it should further be clear and made transparent how these are used in policy determination - and this is often not the case [4]. Policy-driven data collection should be improved for more effective adaptive governance. Recommendations in [4] include making more use of secondary data, and more transparency in data-sharing and decision-making.

This highlights different challenges that current official data production processes are confronted with in relation to the different purposes of the policies that seek 
to promote more adaptive governance approaches and associated monitoring regimes. Environmental policies will increasingly need to make room for increased accountability, public awareness and engagement, reframing the problem from an environmental problem to one of human-environment interactions in necessary.

Given increasing calls for more adaptive governance approaches in social-ecological systems, at least five different purposes for developing data for the evidence base of related environmental policies and regulations can be distinguished:

1. Compliance with EU law by EU Member States and compliance with national regulations in different areas of a country and windows of accountability on local and national governments in terms of the effectiveness of their governance approaches.

2. Opening new windows of accountability relating to causes for environmental degradation such as pollution emissions.

3. Communications on the state of the environment to a wide range of stakeholders and in and the general public for awareness raising.

4. Public engagement to identify potential local action fields for environmental protection and regenerative activities and actively and meaningfully engage in such action.

5. Participatory evaluation and normative reframing for the development of new and improvement of existing policies and implementation measures.

The subsequent sections compare the merits and limitations of citizen science and traditional official data production approaches in relation to each of these purposes. In order to structure the discussion in more concrete terms we relate the comparison mainly to the case of water governance under the 2000 EU Water Framework Directive, as well as to a research project on the deployment and co-design of citizen science tools for adaptive governance and social learning for improving water quality in Luxembourg.

The analysis and interpretations presented in the following sections of this paper are based on literature review, documentary review of relevant policies and legislation. Furthermore, we relied on interviews with key actors in water governance in Luxembourg to establish their views on merits and limitations of official data and production processes on water quality questions, as well as differing viewpoints on the potential of citizen science to complement such official processes. The project also involved participatory actions to engage volunteers to analyse water quality across Luxembourg using citizen science tools from the Non-Governmental Organisation (NGO) FreshWater Watch, as well as two workshops to co-design new sets of indicators for water governance.

\section{Citizen Science: Its merits, limitations, risks and opportunities}

There is a large rage of different definitions of citizen science in the academic literature and in an increasing number of government reports on the matter (reviewed in [10]). Most definitions describe citizen science as a process of scientific inquiry that involves the cooperation between members of the public and professional scientists. While public participation in scientific projects has a history dating over 100 years (e.g. the Annual Christmas Bird Count dating back to 1900 [11]), it has recently gained much prominence. This is largely due to accelerating technological innovations in sensor technologies, as well as open source software tools easily adapted for diverse monitoring purposes to combine sensor-derived data, photographs, and the input of subjective data, allowing usage by citizens and researchers with little computing knowledge $[12,13]$.

Different forms of citizen science can be distinguished based on how volunteers engage in the scientific inquiry. One simple way to draw this distinction is to differentiate between contributory, collaborative and co-created citizen science [14]. Haklay [10] distinguishes six types of citizen science activities, differentiated depending on the role of citizen volunteers in such projects. In 'contributory projects', scientists scientist solicit specific observations, either with or without technological sensors, from the community of engaged volunteers. Volunteer participants can also be called upon to process the data, in particular where more complex pattern recognition tasks need to be exemplified with the human brain first, as primers for machine learning. Collaborative projects rely on greater degrees of interaction between scientist experts and engaged citizens and stakeholders. The last level, sometimes referred to as civic/community science, or co-created projects, involves projects driven by a group of engaged citizens (this can include nonexperts and experts) who identify a problem that is a concern for them all, and address it using scientific methods and tools. Within this type of activity, the problem definition, data collection, and analysis are carried out by community members who solicit the advice and contributions of scientists or established laboratories. 
On the one hand, it is often easier to solicit input from greater numbers of citizen volunteers on short simple tasks; volunteers invariably learn and have a greater awareness of associated issues after having contributed to collecting or making meaning of data. On the other hand, higher levels of engagement for the co-creation of the research questions, and appropriate data sets and processes for data collection promise greater empowerment of citizens to engage on environmental matters and to shape the evidence base they may need for their actions in collaboration with or based on contributions by scientific experts. Such projects have a greater potential to contribute to social innovation for sustainability transformations of prevailing social practices [15] and thereby promising the largest impacts on education, public engagement, and social well-being [16]. For the purpose of this paper we can conclude that different forms of engagement can serve different purposes ranging from fostering public awareness to co-creating spaces for the normative reframing of the evidence base for policies and as such potentially lead to opportunities for reframing the policies themselves.

While citizen science has become increasingly popular across an array of scientific disciplines, this is especially the case in environmental monitoring, in fields such as conservation biogeography [17] hydrological hazards [18-20] and the pollution of surface water and associated ecosystems, which is the subject of the work presented here. The rapid growth of citizen science projects has led to suggestions that they could be used for complementing the traditional data production process in relation to the UN Sustainable Development Goals [21]. These SDGs form the basis for the 2030 Agenda [22] and require statistical performance indicators to quantify progress. The Global Indicator Framework (GIF) designed for this purpose contains 231 unique indicators, many of which are produced rarely, if at all [23]. For example, indicator 6.3.2 is the "Proportion of bodies of water with good ambient water quality". However, the official UN portal (https:// sdg6data.org/indicator/6.3.2) shows the result for less than 40 countries, with "data not available" for the vast majority. Similarly, for indicators concerning drinking water quality, a recent study [24] shows that more than 30 countries have conducted water quality testing in household surveys in many cases generating representative data for the first time.

Data used to calculate these statistical indicators principally come from databases maintained by governments and national and/or international statistical offices. While these traditional data sources are valuable and necessary, it has been put forward that they fall short of the requirements for meaningful SDG-reporting and the associated policy making [21]. Among the issues raised in justifying this claim are the large costs associated with obtaining these data, and the resulting infrequency of resampling, resulting in data often being outdated. Furthermore, data registered at a national level do not reflect any variations inside the particular country. These, and other issues, have led to the development and application of new types of data sources, such as satellite image data, which is fast becoming a "traditional" data source, commercial data [25], and citizen science, which forms the basis for the research presented in this paper.

However, there are also several challenges in developing citizen science projects outlined in the literature, which point clearly to the complementarity of citizen science and traditional approaches to collecting data for the evidence-base for policies, but also highlight that citizen could never replace national and other official data collection and processing techniques.

\subsection{Can citizen science contribute to monitoring for national compliance with EU law?}

A study of the potential of citizen science to contribute to SDGs [26] found that while it already now contributes to 5 indicators (mostly regarding ecosystem protection), it has the potential to make an impact to 76 further ones. The study further demonstrated that the indicators within SDG 6 (Clean Water and Sanitation) are among those which could benefit the most from citizen science. A recent study [27] has demonstrated how citizen science monitoring programmes can contribute to SDG reporting, specifically targeting the aforementioned indicator 6.3.2 regarding clean water bodies in Ireland. These authors put forward that samples measured by citizens cannot provide exact numerical values of the measured parameters, instead indicating a concentration range. They thus conclude that citizen science is more applicable to a monitoring methodology in which the focus shifts from target values to target ranges, allowing for the easier integration of citizen science data with that of professionals. This study was done in the framework of FreshWater Watch (FWW), a global citizen science project supporting community monitoring of freshwater quality.

Among other examples concerning the monitoring of water bodies and associated ecosystems, also in the FWW framework, is a study of nitrate pollution in the Thames basin in England [28]. These authors note that 
the national Environmental Agency (EA) is under obligation to sample all catchments. However, due to limited resolution of sampling, they demonstrate how pooling and integrating data from various sources can remove bias and increase the statistical power of the data. Citizen science data was also used to map nutrient concentrations in water systems in Brazil and Mexico, and to show how these data are critical to guide land use planning and avoid the undesirable consequences of artificial eutrophication [29]. These authors are also clear that such data should only be drawn upon in support of regular monitoring activities, but not to replace official data.

One of the key differences between data collected in citizen science projects and more traditional ones is the resolution of the datasets, both spatial and temporal. Whereas traditional datasets usually have a regular spacing, citizen science projects tend to have finer, though irregular, sampling density, with a high amount of data collected in a particular area of interest. An example is the soil moisture index calculated by the European Drought Observatory [30], with a value calculated on a $5 \mathrm{~km}$ grid. With this index covering the whole of Europe these data are vital for modeling large scale trends, but are of no use to individual landowners in Luxembourg, where the development of a drought early warning system would require community-based soil measurements.

Regular sampling rates are often a requirement for a meaningful trend analysis, and the often-irregular nature of citizen science data sets has been one of the key barriers to the acceptance of citizen science [31]. The issue has been recognized, and methods to allow citizen science projects to move beyond "haphazard sampling" have been put forward [32]. For citizen science to reach its full potential, the issue of resolution must be clearly incorporated into the planning stage of a project. An example of this is a study nitrate of phosphorus pollution in Brittany, France, where data was collected by high school students between 1998 and 2016 [33]. Rigorous planning and continued institutional support have allowed the authors to demonstrate that citizen science projects can present high quality data on regular timescales and improve public engagement with socioecological issues.

\subsection{Building public awareness of and trust in the evidence base for policies}

There are often concerns associated with data quality. Studies based on citizen engagement with data are often treated with mistrust, with concerns about the data quality both by expert scientists and officials engaged in data production and interpretation, as well as by citizens at large [34]. As data collection by inexperienced participants can indeed introduce faults, biases or skew data, at the level of sampling, documentation and interpretation, approaches for developing simple Standard Operating Procedures, training sessions, and validating citizen data have been developed $[35,36]$. Most errors in citizen science projects are random, and their possible prevalence depends on the level of involvement of citizen scientists. Mistakes can potentially be introduced to the observation process, either through recording incorrect data, or not following the sampling protocol. Non-random errors are also possible. The nitrate concentration in the Thames study [28] notes that most citizen scientists collected samples in spring and summer, resulting in a form of fair-weather bias, which, if not attended to, could have grave consequences for the results of a hydrological project.

The key to making citizen science data trustworthy is being aware of all possible sources of error, and development of statistical tools for validation. A review of such tools [35] concluded that citizen science databases present an exciting opportunity for collaboration between statisticians and environmental scientists.

Another issue often alluded to is mistrust from public officials that non-expert volunteers can interpret results from single measurements and time series or comparing different measurements across space in a meaningful manner. Such challenges can for example be addressed in a careful co-design process on a web platform that serves to represent empirical evidence in different ways for different purposes and different communities. Attention to including metadata also on uncertainties associated with measurement series in an obvious manner is key.

\subsection{Public engagement and empowerment for action and normative reframing of policies}

Increasingly diverse data landscapes emerging from the growing array of new possibilities from taking data from traditional and non-traditional sources into account will give rise to new opportunities to analyse patterns of behaviour and how to change them as emergent properties of complex social-ecological systems. But the demanding task of co-designing and assuming new responsibilities in the quality control of diverse data landscapes that can serve as sources for the evidence base for policies poses also significant new challenges 
to policy makers. If there is a desire to move from expert-driven technocratic governance models to more democratic models in which also underlying knowledge and problem framings are co-created - as part of a more deliberative democracy approach - this will require significant capacity building of officials in ministries and in national and the European Statistical System in multi-criteria analysis to take into account such data sources in policy and decision-making in a transparent and accountable manner.

In such cases it is recommendable that any data production process that relies in part on the co-design of data sets for diverse purposes and the data coproduction with volunteers should also have a social dimensions, involving, workshops, where people including experts and non-experts meet to jointly make meaning of the data pool to draw insights to inform concerted or individual action every one or two years.

These considerations on the complementarity of official data production and citizen science approaches for the various purposes are now analysed in more detail and concrete terms with reference to the case of water governance. Section 4 focuses on limitations of the current water governance approach with reference to the 2000 EU Water Framework Directive with respect to requirements arising from comparison of the current situation with ideals outlined in the literature on adaptive governance processes. Section 5 presents a critical discussion of research on developing diverse forms of citizen science projects to foster public awareness and engagement in water governance in Luxembourg.

\section{Environmental data production and usage for evidence-based policy making and practice: The case of the 2000 EU Water Framework Directive}

Surface water bodies are exposed to many stressors. Population growth, in combination with the drive for economic growth and concomitant intensification of (agricultural) production, land-use change and emissions from our socio-industrial metabolism greatly increase the risk of deteriorating water quality and water over-extraction, and associated loss of biodiversity in aquatic ecosystems [37]. One particularly salient issue in Western Europe is that high levels of nutrient influx mainly in the form of nitrates and phosphates cause 'eutrophication', that is disproportionally fast growth of certain algae that thrive on nitrates and phosphates that then spread and crowd out other aquatic organisms in surface water bodies [38]. The excess nutrients largely result from human settlements, agricultural production and forest management activities.

The EU Water Framework Directive (WFD [39]) has been described as one of the most comprehensive and ambitious pieces of environmental EU legislation that significantly extends the scope of water governance and management [40]. It obliges member states to prevent further deterioration, to protect and gradually improve the status of water bodies to reach "good status" by 2027 . This status is determined by aggregation of chemical, hydromorphological and ecological criteria. Building on the pollution control standards stipulated in the EEC Wastewater Directive [41], a directive was published specifically to address nitrate pollution [42]. The WFD furthermore encourages member states to integrate water protection in policy areas such as energy, transport, agriculture, fisheries, regional policy and tourism, signaling a move towards an "integrated Community policy on water" and explicitly evokes one of the cornerstones of adaptive and integrated water governance and management that prioritises pollution prevention over technological fixes [43]. So it is of particular interest to explore the interplay between the approaches to implementation and the evidence base that is produced in support - in order to ensure an appropriate level of concreteness, we refer to the research on implementation and factors facilitating and hindering it in the national setting of Luxembourg, and in particular two river basins there.

\subsection{Compliance with EU law and national regulations - trend sensitive data?}

In the EU Water Framework Directive, the assessment of the ecological status of surface water bodies builds on a common definition and a five-step scale that member states are required to apply (high, good, moderate, poor, bad). The quality elements assessed are:

- Biological quality: composition and frequency of species of aquatic flora (phytoplankton) and fauna (e.g. macroinvertebrates and fish) according to water body types and the established "reference status".

- Physico-chemical quality: general quality elements (temperature, oxygen, nutrition) and specific (synthetic and non-synthetic) pollutants (e.g. pesticides).

- Hydromorphological quality: flow regime (hydrology), direction and speed of run-off, structure of riverbed (morphology: depth, width, structure and substrate), structure of riverbank. 
Table 1

Scale of nitrate and phosphate-phosphorus concentrations in relation to surface water quality

\begin{tabular}{llllc}
\multicolumn{1}{c}{ Indicator } & Very good & Good & Moderate & Bad \\
\hline Nitrate $\left(\mathrm{NO}_{3}\right)[\mathrm{mg} / \mathrm{L}]$ & $\leqslant 10$ & $\leqslant 25$ & $\leqslant 35$ & $>35$ \\
Nitrate-nitrogen $\left(\mathrm{NO}_{3}-\mathrm{N}\right)[\mathrm{mg} / \mathrm{L}]$ & $\leqslant 2.3$ & $\leqslant 5.7$ & $\leqslant 11.3$ & $>11.3$ \\
Phosphate-phosphorus $\left(\mathrm{PO}_{4}^{3-}-\mathrm{P}\right)[\mathrm{mg} / \mathrm{L}]$ & $\leqslant 0.05$ & $\leqslant 0.15$ & $\leqslant 0.30$ & $>0.30$ \\
\hline
\end{tabular}

The Water Framework Directive outlines three strategies for data collection. In most EU countries, as in Luxembourg, data collection is coordinated and centralized by a dedicated public water authority. In the case of Luxembourg this is the Water Management Authority (Administration de la gestion de l'eau - AGE). First, investigative control involves the development of longitudinal profiles to research pollution and pollution sources, monitoring, among others, polycyclic aromatic hydrocarbons, metals, and pesticides alongside the general physico-chemical indicators. Second, monitoring control is built to provide a broad picture of the state of the entire surface water network, and samples are taken every month. As the prime framing of questions concerns national compliance with EU environmental legislation, the costly data collection process is designed to make statements for a large territory often resulting in poor density of sampling of official data points for continuous monitoring over time. For example, in Luxembourg there are five active monitoring stations, strategically positioned to represent the entire surface water network in Luxembourg (two on the Sauer, one each on Alzette, Syre and Chiers rivers). Third, operational control is a monitoring activity, which takes place within a specified timeframe and, in general, is concerned with surface water bodies that are in risk of non-compliance with environmental standards or to track the impact of implemented measures.

The main parameters of concern in this case study are the nutrients nitrates and phosphates in surface water, excessive levels of which in water can lead to eutrophication.

The European Commission set the thresholds of $25 \mathrm{mg}$ of nitrate $\left(\mathrm{NO}_{3}\right)$ and about $5.7 \mathrm{mg}$ of nitratenitrogen per litre as a guideline concentration [44]. However, environmental NGOs point out the sensitive species such as some freshwater muscles may already be displaced by other species thriving at nitrate levels as low as $10 \mathrm{mg} / \mathrm{L}$. As part of the implementation of the WFD, the AGE has also set a scale for the concentrations of nitrate with below $25 \mathrm{mg} / \mathrm{L}$ as indicating good status, and $35 \mathrm{mg} / \mathrm{L}$ as the threshold above which quality is unsatisfactory [45]. Phosphate-phosphorus concentrations are more difficult to quantify, but indicative thresholds were published by the European
Environment Agency [44] on nutrient concentrations in Europe's freshwaters. A threshold of $0.1-0.2 \mathrm{mg}$ phosphate-phosphorus $\left(\mathrm{PO}_{4}^{3-}-\mathrm{P}\right)$ per litre was put forward as sufficient to lead to eutrophication in freshwater resources. Along these lines, the AGE associates quality status with phosphate-phosphorus concentrations. It sets the threshold for good water quality in terms of phosphate-phosphorus at $0.163 \mathrm{mg} / \mathrm{L}$. This approximately corresponds to the $0.1-0.2-\mathrm{mg}$-per-litre-limit fixed by the European Environment Agency mentioned above. The relevant thresholds are listed in Table 1 .

The main challenges to any data collection and monitoring regime to assess water quality are associated with very wide ranges of natural variability of the individual parameters, further exacerbated by anthropogenic influences that are also subject to significant variation. Most parameters in relation to water quality vary depending on the time of the day, the weather, the seasons, as well as geo-spatial/locational considerations such as the geo-morphology of the water course and whether it was changed (e.g. straightened). Other important factors are what sort of human activities take place in proximity to the water body, such as settlements, is there a water treatment plant, or are there agricultural fields, what crops with what cultivation approach? Accordingly, the first significant challenge in the face of such variability is to inform a statistically meaningful trend analysis. The quantity of samples that have to be collected, analysed and results of which would need to be interpreted over time to track any changes over time in a statistically significant and meaningful manner is unaffordable in most countries. Furthermore, this has great repercussions on the degree of measurement, or even estimation, of uncertainties for each parameter.

A particular issue concerning Luxembourg is its small size, which can lead to it becoming a statistical anomaly. This is well illustrated with the example of nitrate pollution in surface water. The most recent Eurostat report on nitrate pollution [46] does not calculate, or present any trends for countries where the number of monitoring stations is less than 10. Luxembourg data is thus not presented, as AGE maintains 5 stations. However, the EC directive [47] requires at least one functioning control station per $2500 \mathrm{~km}^{2}$, so under these 
regulations Luxembourg would thus theoretically be required to have just a single station.

A further issue associated with the chosen approach to definition and representation of the status of water bodies is that the high level of aggregation of data produced on diverse parameters within each quality dimension (chemical, ecology, geo-morphology) means that the determination per se that is often visualized for purposes of communication hides causes and precludes meaningful deliberation on possible actions for improvement. It is challenging to develop a detailed understanding of the environmental impacts and consequences of performance of policies and implementation measures given the difficulty of developing data sets, statistics and indicators that are trend sensitive in such cases.

\subsection{Enhanced accountability relating to pollution}

In order to produce data for an enhanced understanding of pollution emissions, in particular those affecting important sites of aquatic biodiversity, the sampling density across space would need to be increased in most if not all EU countries, including in Luxembourg. The prescribed activity of operational control monitoring under the WFD mainly serves this purpose. It takes place within a specified timeframe and, in general, is concerned with surface water bodies that are in risk of non-compliance with environmental standards or to track the impact of implemented measures.

However, whilst the EU WFD mandates sampling of larger water bodies, ecosystems with particularly high biodiversity are also often found in smaller streams. The WFD greatly increases the need for scientific research as regards the above-mentioned aspects [48], with some member states entering largely unknown territories. In Luxembourg the main institutions conducting scientific research are the Luxembourg Institute of Science and Technology (LIST), and the University of Luxembourg (UL). These both have formal agreements with AGE, allowing for project funding. Further projects can be funded through the national research foundation (FNR) or EU institutions.

\subsection{Communication for public awareness}

Provisions for public access to environmental information of the WFD are largely developed based on the Aarhus Convention of the United Nations Economic Commission for Europe [49], which is one of the most far-reaching intergovernmental treaties on environmen- tal rights. Among others, it guarantees access to environmental information, encourages public involvement in decision-making and gives the public the right to challenge environmental decisions [48].

But what does that mean in practice, and how are these lofty goals realized in terms of implementation measures? In the case of Luxembourg for example, Geoportail.lu is the main repository of publicly accessible geospatial information. It shows the results of evaluations of water quality in a map of the rivers of Luxemburg that are subject to monitoring, using simple colour codes (traffic light logic) for easy visualization. However, in interviews, most officials were very worried about misinterpretation of such coarse representations of such complex data. For this and similar reasons the Ministry for the Environment and the AGE regularly publish reports that are more narrative and provide more context and qualitative descriptions of the state of Luxembourg water bodies and which may be improving or deteriorating based on their data sets. Individual measuring results are rarely communicated, as many experts fear misinterpretation of outliers by the general public potentially leading to scare mongering.

The same applies to other data publication efforts, such as by drinking water syndicates. Most other organisations, including nongovernmental ones, choose to focus on the publication of tailored information, such as in the form of brochures. This format is widely used to raise awareness and inform on a particular and often pressing issue. It is often part of governmental awareness raising campaigns. Benefits of this approach are that the public gets well-presented and thought-through information, which means that the likelihood for misinterpretation is very low.

Activity reports by individual organisations and municipalities can contain datasets, if monitoring has been part of the yearly activities. Often, however, although the data is physically accessible to anyone who is interested, meaning is, generally, not conveyed simultaneously. Therefore, interested parties need to decide on the data's meaning on their own, with methods such as further research. From interviews it was deduced that the organisations do fear misinterpretations, which could potentially lead to panic when a value for an indicator crosses a threshold, and the organisations' capacity to explain a high reading is also limited in terms of man-power as well as interpretative depth.

To give adequate information needed for an adequate interpretation of the data seems out of scope of the missions of the different organisations. These are rigid as based on law and also encompass mostly essential 
Table 2

Data publication channels by actor

\begin{tabular}{|c|c|}
\hline Actor & Data publication channels \\
\hline Ministry & Reports, website, brochures \\
\hline AGE & $\begin{array}{l}\text { Geoportail.lu, Inondation.lu, reports, other } \\
\text { publications and brochures }\end{array}$ \\
\hline LIST & Atlas hydroclimatic, scientific publications \\
\hline UL & Scientific publications \\
\hline WW Synd & Reports, Syndicate websites \\
\hline DW Synd & Reports, website Drenkwaasser.lu \\
\hline SEBES & Reports, website sebes.lu \\
\hline $\begin{array}{l}\text { Communes } \\
\text { Other }\end{array}$ & Reports, Commune websites \\
\hline
\end{tabular}

missions, of which educating the public in the interpretation of environmental data is not part. Most data are collected, and from the interviews it appears that not all data is stored in one place, let alone publicly accessible. Several interviewees from NGOs and research organisations also remarked that upon requests for specific data sets for specific purposes, there are extensive time delays for the provision of official data that is not publicly accessible, if it is provided at all. The channels of data publication of the actors discussed here can be found in Table 2.

\subsection{Public engagement and empowerment}

The WFD was one of the first EU directives placing emphasis on the need for public participation in environmental governance [48,50-53]. This introduction can be interpreted as a partial departure from a hierarchical mode of water governance towards network governance. A further document, the WFD guidance on public participation [47] provides assistance to member states in the implementation of the provisions on public information, consultation and active involvement of all interested parties. This document explicitly underlines the value of local knowledge and the knowledge of those affected by policies in decision-making. As a minimum requirement, member states have to formally consult the public on the production, review and updating of these plans. In addition to formal consultations, the directive stipulates that background documents and information used in the production of the management plans should be made available on request.

In Luxembourg, public engagement is possible through the River Partnerships (RP). These initiatives are based on the collaboration between communes, intercommunal syndicates, and associations from the water domain, and are tasked with bringing the actors in the water domain and the public together to inform and raise awareness on the integral and global management of the water cycle. RPs can plan and implement technical measures with or without collaboration with the AGE. In addition to improving the state of the local freshwater networks, their further mission is to raise awareness, educate, and inform. Data collection is then used as a tool for to support the planning, implementation, and follow-up of technical measures, as well as a way for the public to physically engage with water to raise awareness or educate on water issues.

Furthermore, amongst environmental NGOs, the most active in the field of water quality is natur\&ëmwelt a.s.b.l. This non-profit organisation campaigns for the protection of the biodiversity of a diverse natural and cultural landscape [54]. Their mission is to raise awareness, to give advice, to conduct practical, scientific, and political work on local, national, and international level. It counts around 11,000 members divided into regional organisations and 40 partner associations.

In general, in order to empower people to take evidence-based action, locally meaningful data would be required here. Often, however, in official processes data on specific parameters is aggregated to high level spatial scales (national or EU) before publication. Current methods do not readily foresee disaggregation of such data to smaller spatial scales. More locally specific data is however required, such that they are indicative of what measures might help improvement of the status of the water body. This would mean that public access to data sets would be most useful if this data could be aggregated and disaggregated across spatial scales.

Moreover, it would be helpful if local communities were empowered to identify promising courses of action, take them, and identify what parameters they might like to measure and how such data and associated uncertainties might best be represented on the web platform to really make meaning of which interventions help or hinder the restoration of diverse and healthy aquatic ecosystem in the face of pressures of excess nutrients and eutrophication. Local measures merging from participatory processes might be as diverse as attempting to reduce nutrient input into sewage treatment plants and the effectiveness possibly by ensuring less rain water dilution of in flux into the plant, and reduction of use in households of compounds that might reduce the efficacy of bacterial sludge for treatment in biological stations, or talking to local farmers and promoting and working with them to reduce nitrate effluents from agricultural fields. Different local sets of indicators could be developed to pursue changes in such specific ways of human-environment interactions, including photos, questionnaires to households. 


\subsection{Opportunities for normative reframing: Improvement of policies and implementation measures}

How indicative are data sets on addressing causes, effects, the degree of adoption and implementation of measures, and the effectiveness of the individual measures on actually improving water quality where they have been successfully implemented? Proper public engagement should ideally allow for not only peer review and evaluation of environmental data, but also for opportunities of normative reframing of the purpose and approaches by policies, as well as of their underlying assumptions and implicit normative goals. This is not common practice as yet, but a first case study of a research project in Luxembourg reveals potential merits and, limitations, challenges and opportunities associated with such practices.

\section{Case study: How can different forms of citizen science contribute towards more adaptive governance of water quality in Luxembourg}

\subsection{Can citizen science contribute to the data pool to enhance compliance and accountability?}

One example illustrating the capacity of citizen science to enrich official data sets in terms of their geographic spread is the FreshWater Watch (FWW) project established in 2012 as part of the HSBC Bank's Water Program. It has since grown and reached global scale. Its main objective has been to enable individuals and groups to monitor water bodies by providing them with the FWW citizen science tool, which encompasses a pool of tests for a great variety of parameters to choose form, generally linked with water quality, as well as the supporting software, including the app for data input and transmission and the web platform for data visualisation [55]. The project has resulted in a range of research publications [56,57] and diverse local impacts [58]. The project's strengths include the geographic reach of the NGO in that it collaborates with local environmental groups in many countries. Limitations of the project that have been noted by some more remotely affiliated research organisations include that training sessions for volunteers are very rudimentary (to keep them short and entertaining) in terms of the information they convey both on the context of water quality and the meaning of individual data points and uncertainties associated with the measurements.
The University of Luxembourg conducts research in collaboration with FWW. The project focuses on using the NGO's tool kit with volunteers in different engagement processes in different forms from contributory to co-creative in order to measuring nitrate and phosphate concentrations in the water bodies as well as turbidity levels. The other indicators are visual and/or estimated by visual indicators. To guarantee a certain quality of the data, citizen scientists participating in FreshWater Watch projects are required to participate in training sessions. The NGO collaborated with experts on water quality to develop standard protocols to ensure the chances for errors in sampling or the interpretation were minimised. All documentation is readily accessible through a website and summarised and accessible on the mobile application.

An example of a contributory project is the citizen science exercise in the Syr river watershed area focusing on three smaller streams. In this project a group of citizen scientists has generated 51 samples distributed across 8 pre-determined sampling sites. As the description of the official monitoring programme shows, this kind of detail, in particular monitoring smaller streams monthly at different locations, is generally not part of national programmes. These kinds of citizen science projects have the potential to complement high-level official monitoring designed to produce overviews with detailed local results.

Another event clearly showing the power to entice volunteers in scientific activities for environmental monitoring was the WaterBlitz 19 where the Freshwater Watch Team coordinated the collection of data on water quality across and beyond Europe. Organised locally by the University of Luxembourg, the WaterBlitz 19 in Luxembourg ran over four days from 20 to 23 September 2019. The overarching goal was to collect as many water samples as possible to develop a high-resolution overview of the state of Luxembourg's surface water bodies. Anyone interested in the event could register to receive a free water testing kit encompassing tests for nitrates and phosphates. Alongside these compounds, observable indicators were part of each data point, including water colour and land use in the immediate surrounding. The data were uploaded using the FreshWater Watch app or online platform. The project developed new knowledge for citizens, science and policy promoted experience-based learning and provided people with the opportunity to learn more about the water bodies in their neighbourhoods.

However, early warning signs for polluting levels of nutrients such as nitrates and phosphates may also be 
detectable without traditional scientific projects, using instead visual observations, documented with photos. For example suspicious pipes with effluents entering a water body may be valuable evidence for possible nondocumented or declared polluting activities. Similarly, after flooding events, tell-tale traces of toilet paper in branches along a river bank may be indicative of an overflow accident in a near-by sewage treatment plant resulting in untreated water from human settlements with plenty of nutrients entering the water body. Citizen science tools can be developed and embedded in the promotional material for nature trails, organized ecotourism tours and other outdoor activities to allow volunteers to photograph suspicious occurrences in strategic locations.

\subsection{Public awareness building}

Different forms of citizen science can be distinguished based on the form of public engagement. One simple way to draw this distinction is to differentiate between contributory, collaborative and co-created citizen science [14]. The WaterBlitz as described above would for example be contributory as experts design and implement the study and volunteers are simply called upon for participatory sensing and providing data.

About 80 people participated in the event, collecting 113 records from 56 water bodies. These data will greatly assist the further investigation of potential pollution hotspots as well as sources, and to further research the nutrient status throughout Luxembourgish water bodies. The interpretation of the records is a very delicate matter, as thresholds can only be applied with limits and the colour scale readings of the indicator strips to determine nitrate and phosphate levels are only an indication of the actual concentration at a given location and time. Following the rule "The more data points exist for a water body, the better the data represents its status", single readings have to be interpreted carefully. Potential errors could originate from manipulation of the sampling tubes, in readings and upload. Occasional errors with the functioning of the tubes also cannot be ruled out completely, and the most appropriate statistical tools need to be carefully picked and their implication for the interpretation considered.

\subsection{Public engagement and empowerment}

Of particular interest for a more systemic approach to collecting data on human-environment interactions is the possibility to combine data collection through the
FreshWater Watch APP and using the FWW Standard Operating Procedures and training materials. In combination with the citizen science tool i-naturalist, this allows for collecting empirical evidence on local species diversity by taking photos and feeding them into a network of volunteers and certified experts who can make determinations of the species (www.i-naturalist.org). Volunteers can thus collect data on physico-chemical properties of water at the same time as documenting the occurrence of particular species and possibly indicator species that allow inferences of particular states of ecosystems and as such collect data that is relevant to two different policy fields relating to water and biodiversity.

Furthermore, there are easy to use plug-ins to configure data collection apps flexibly for a wide range of entries of different sort of empirical data. This included photos, and qualitative observations on any other salient aspects of human environment interactions that the local community would like to document as evidence base for evaluating jointly how they engage in sustainable water governance.

For proper public engagement and empowerment of volunteers to better understand their action potential and impacts when seeking to address water quality issues in their neighbourhoods or local river basin, the goal would be the establishment of co-created projects. This involves diverse participants with disparate interests and expertise in the design and implementation of action, experimentation and monitoring for sustainable water governance, locally in their river basin. There are an increasing number of initiatives to co-create citizen science projects with local communities on top and science on tap. With this goal in mind, in Luxembourg, a series of co-design workshops engaging local communities was organized in the framework of the NEXUS FUTURES Project on sustainable water and land use.

In these co-design workshop all elements of the project we considered together: relevant actors, indicators, user groups and data users. The actors for the project were arranged according to their level of interest and influence, with their roles and motivations documented. In a second step, indicators for a citizen science tool were developed, based on an exchange of personal experiences of those present in the region on changes and the need for documentation.

First meetings with the Natur- und Geopark Müllerthal revealed that a protection and renaturation project could benefit from a link with citizen science. In addition to governmental agencies relevant user groups would be schools as well as the general public. Sugges- 
tions for indicators included both biophysical quantities as well as personal observations and assessments of locations, abnormalities and changes. Quantifiable biophysical indicators were: temperature, $\mathrm{pH}$ value, water hardness, bulk material and biodiversity. Personal observations and assessments would also be noted as a "feel-good indicator". In this way, citizen scientists would be invited to reflect on their impressions, their relationship to and how they feel at the various sources. The feel-good indicator could help to create awareness and knowledge, for example how different places in nature influence our well-being. This would also counteract concerns that the environment is not being properly perceived at the expense of using smartphones.

In sum, workshops with local organisations with an interest in water quality regeneration suggest that in particular in relation to water protection areas for water sources, and renaturation projects of altered river courses, the development of a citizen science tool kit and a web platform to share co-created data was deemed most interesting for engaging diverse volunteers in such activities. Desirable indicators spanned a wide range from biophysical and ecological parameters, to ones for the nature of humanenvironment interactions such as the presence of litter, or a well-being indicator that gets people to sense, make observations, reflect on and evaluate the environmental quality at different water sources.

To summarise, in these projects we have identified three ways in which citizen science can foster improvement of policies and implementation of measures as relevant here.

First, new windows of accountability as incentive for best practice and courage for social innovation: It seems self-evident that the engagement in any form of citizen science by volunteers on water quality will trigger reflection and learning and critical thinking about the state of water in local water bodies, as well as the effectiveness of the current government approach. New windows of accountability are flung open on the work of relevant ministries and administrations to complement their own public reports. Moreover, for local public projects engaged volunteers can make involved parties such as municipal officials and land owners more accountable for the quality of implementation of possible measures for the improvement of water quality, such as renaturation projects along privately owned river banks that require collaboration and compromise. Thus reputational risks associated with such projects rise, which may be beneficial for their implementation.

For enhancing public awareness as well as empowering local communities to act and monitor impacts of their actions, different approaches to designing citizen science projects have diverse merits and limitations. From the presented citizen science projects in Luxembourg it clearly emerges, that diverse forms can be complementary. A Waterblitz can serve to engage many volunteers over a very short time period. It is much more difficult to find engaged volunteers ready to commit in more complex and longer projects that involve co-design, as well as co-creation of data and knowledge over time.

However, co-created projects that provide spaces to question and reflect on existing data and open spaces to leverage very diverse perspectives, interests and expertise to 'reframe' the purpose and nature of policies, implementation measures and data pools from current data production regimes - are necessary for societal advancement and more fundamental sustainability transformations. Spaces for reflection and critique and ways that these are connected with water governance in a multi-level governance system at the municipal and national level are key for learning at a systemic and societal level [59].

\section{Conclusions and outlook}

In sum, the comparative analysis presented in this paper of the official data processing network and the promise citizen science holds based on first practical experiences with it, shows that the current official data landscape is clearly dominated by organisations with a focus on national interests rather than those with stronger local interests, with significant amounts of water data being collected by national authorities. Monitoring control only focuses on the main surface water bodies in Luxembourg, smaller streams are neglected, regardless of whether they are in biodiversity rich areas or not. In addition, operational control, even though more detailed, is by definition an irregular and somewhat rare endeavor.

It is thus apparent that there is a need for a diversified data pool, especially as the EU WFD states that water governance is participatory and concerns everyone as a stakeholder, and if one purpose of environmental policy-making is to create more diverse action fields for individual citizen to engage in and empower them to take action. This will require some institutions and processes for social learning to ensure there are ways to coordinate action and the data production for the evidence base for such action.

We have demonstrated that citizen science has the potential to complement official data pools in meaning- 
Table 3

Summary of the comparative analysis of the performance of the official data production process on water quality with a focus on nitrate and phosphate levels and citizen science in relation to diverse purposes as described in the EU WFD

\begin{tabular}{|c|c|c|c|}
\hline Purpose & $\begin{array}{l}\text { Official } \\
\text { data }\end{array}$ & $\begin{array}{l}\text { Citizen } \\
\text { science }\end{array}$ & $\begin{array}{l}\text { Investments required to harness the potential of } \\
\text { citizen science for water governance }\end{array}$ \\
\hline $\begin{array}{l}\text { Compliance with the WFD - requires trend } \\
\text { sensitive data }\end{array}$ & + & -- & $\begin{array}{l}\text { Development of quality criteria and quality control processes for greater } \\
\text { acceptance of citizen science as a data source }\end{array}$ \\
\hline Accountability & + & ++ & $\begin{array}{l}\text { Coordinated co-design of citizen science approaches and capacity } \\
\text { building in official national and EU statistical systems for engaging in } \\
\text { quality control }\end{array}$ \\
\hline Public awareness & + & +++ & $\begin{array}{l}\text { Targeted policies and implementation to embed citizen science for water } \\
\text { monitoring in regular practice, for example in the school curriculum }\end{array}$ \\
\hline Public engagement in action/empowerment & - & ++ & $\begin{array}{l}\text { Establishment of web platforms and social processes possibly } \\
\text { institutionalised as interconnected living labs and citizen observatories } \\
\text { that link local data co-creation to local action and monitoring of effects }\end{array}$ \\
\hline $\begin{array}{l}\text { Reframing and improvement of policies, } \\
\text { measures and production of the evidence } \\
\text { base }\end{array}$ & -- & + & $\begin{array}{l}\text { Investment in connected social processes across the EU, such as regular } \\
\text { (annual/biennial) deliberative workshops linking meaning-making of } \\
\text { data co-creation and diverse view on what 'progress means' that connect } \\
\text { across governance levels and localities }\end{array}$ \\
\hline
\end{tabular}

ful ways, especially if the data co-creation process is designed in view of servicing multiple purposes (see Table 3) and different target audiences in terms of how data is made accessible and represented. It is not contended here that citizen science should substitute official monitoring. It is not possible to monitor the same, high, number of parameters, measuring some of which requires high levels of expertise and sophisticated equipment. Citizen science allows to develop a different, but overlapping range of indicators, and in this way, deliver additional, complementary, data points.

Whilst trend sensitivity for parameters with high levels of natural variability will always remain an issue, there are compelling examples in which citizen science extends the range of spatial coverage of samples in a meaningful manner. For example, helping to increase the number of sampling points on surface water bodies and/or sampling frequencies in particular pre-defined areas. This would be especially interesting for the surface water bodies, which are not monitored at relatively short intervals, or at all (e.g. smaller streams that are not monitored for researching the state of the watershed areas of the main national surface water bodies). In this way, citizen science could help to develop a more detailed understanding of the state of our surface water bodies as individual river or stream segments, and as a drainage network. And this not only benefits this the official data pool - that can be aggregated for policy making at national and international levels.

On the topic of public engagement this pilot study has clearly shown that the publication of data on water quality is seen as a sensitive matter that gives rise to controversy. In spite of the fact that publication of environmental data is a legal requirement. Many of the interviewees voiced concerns, for example, regarding misinterpretations, panic, and requests for explanations, which cannot be fulfilled in a satisfactory way. Linked with the challenge of adequate interpretations and uses of growing data sets, it is, therefore, imperative to start developing mechanisms and methods to present data sets accounting for these fears that is with meaning. Citizen science can play a significant role by closing the data gap as mentioned above to work towards better interpretations, but also by increasing science literacy among the public, as well as co-creating approaches to data publication jointly with citizens.

But if the data co-creation process is organized for it, it may also allow to access the data bases and display smaller sets of data at a lower level of aggregation across space to be more informative on local circumstances. Rethinking the current official data production process will require serious consideration of different quality criteria depending on different purposes and different target audiences for which data is produced. Investments into capacity building of data experts in statistical systems at national or EU level to get engaged in quality control will be recommendable.

Furthermore, the organization of data pools and working with different sets of data pools from traditional and non-traditional sources, in view of a rapidly diversifying data landscape that policy makers are confronted with will also require some capacity building in multi-criteria analysis for transparent and accountable policy and decision-making.

Last but not least, high density place-based data collection efforts over sustained periods of time are rare, and happen, in general, only on project-basis by, for example, the AGE in case of accidental pollution or the 
River Partnerships or natur\&ëmwelt in view of implementing measures. Here, citizen science can play an important role in closing this gap, in particular as meaningful interpretations are dependent on local knowledge and circumstances. For truly more distributed water governance systems that empower citizen volunteers to design, take and monitor impacts of action in an evidence based and concerted and networked manner citizen science is a sine qua non.

As the current data processing network is characterised by a certain degree of rigidity relating to missions as well as monitoring programmes and indicators, many of the organisation involved are not wellsuited to cater for the reality of rapid changes. Virtually all actors have legally binding reporting obligations, which, if not met, might result in sanctions. With resources often close to being exhausted, data collection programmes are often defined by obligations and become tick-box exercises, potentially hindering innovation and meaning-making. Citizen science projects where participants are actively involved in not just data collection and processing, but also interpretation, have the potential to address these issues.

Citizen science projects also have the potential to build lasting relationships with local stakeholders, which would benefit the development of more adaptive approaches to environmental governance and concrete locally designed implementation projects through which local interventions for regenerating water quality or other aspects of environmental quality such as regenerating biodiversity can be implemented and monitored for their effectiveness. Also for projects to build local resilience to climate change and drought risks, such initiatives and more adaptive governance modes are deemed critical. The role that citizen science can play in regenerating ecosystems in water and on land to become more resilient to climate change and summer droughts in particular will certainly be subject to further research. Involvement of the local population in all stages of one project would increase their interest in participation, often crucial to the project's success, in further ones.

Further investment in research and development in this area is warranted, as more distributed and local approaches to water governance in our era of accelerating and interconnected global and local change arguably are our main chance for developing more resilience in the ways we interact with the natural environment in general and our water bodies in particular.

\section{Acknowledgments}

We are grateful to all participants in interviews, the workshops, and the WATERBLITZ events without whom this research project would not have been possible. We also thank the anonymous reviewers for their helpful comments for improving the earlier versions of the paper.

The research towards this paper was financed through the University of Luxembourg's fund for interdisciplinary research supporting the WATGOV research project that provides for the position of a Ph.D. candidate and the NEXUS FUTURES Project that is funded by the Luxembourg Ministry for the Environment, Climate and Sustainable Development.

\section{References}

[1] Ison R. Governing the human-environment relationship: systemic practice. Current Opinion in Environmental Sustainability. 2018; 33: 114-123. doi: 10.1016/j.cosust.2018.05.009.

[2] Grove JH, Pickett STA. From transdisciplinary projects to platforms: expanding capacity and impact of land systems knowledge and decision making. Current Opinion in Environmental Sustainability. 2019; 38: 7-13. doi: 10.1016/j.cosust.2019.04. 001.

[3] Pahl-Wostl C. Transitions towards adaptive management of water facing climate and global change. Water Resour. Manag. 2007; 21(1): 49-62. doi: 10.1007/s11269-006-9040-4.

[4] Waylen KA, Blackstock KL, van Hilst FJ, Damian C, Horvath F, Johnson RK, Kanka R, Külvik M, Macleod CJA, Meissner K, Oprina-Pavlescu MM, Pino J, Primmer E, Risnoveanu G, Satalova B, Silander J, Spulerova J, Suškevičs M, van Uytvanck J. Policy-driven monitoring and evaluation: does it support adaptive management of socio-ecological systems? Science of the Total Environment. 2019; 662: 373-384. doi: 10.1016/j.scitotenv.2018.12.462

[5] Österblom H, Folke C. Emergence of global adaptive governance for stewardship of regional marine resources. Ecology and Society. 2013; 18(2): 4. doi: 10.5751/ES-05373-180204.

[6] Schultz L, Folke C, Österblom H, Olsson P. Adaptive governance, ecosystem management, and natural capital. PNAS. 2015; 112(24): 7369-7374. doi: 10.1073/pnas.140649.

[7] Vinke-de Kruijf J, Kuks SMM, Augustijn DCM. Governance in support of integrated flood risk management? The case of Romania. Environ. Dev. 2015; 16: 104-118. doi: 10.1016/j. envdev.2015.04.003.

[8] Folke C, Hahn T, Olsson P, Norberg J. Adaptive governance of social-ecological systems. Ann. Rev. Environ. Resour. 2005; 30(1): 441-473.

[9] Hahn T. Self-organized governance networks for ecosystem management: who is accountable? Ecology and Society. 2011; 16(2): 18

[10] Haklay M. Citizen Science and Policy: A European Perspective. Washington, DC. Woodrow Wilson International Center for Scholars, 2015.

[11] Stewart PA. The value of the christmas bird counts. The Wilson Bulletin. 1954; 66(3): 184-195. 
[12] Silvertown J. A new dawn for citizen science. Trends in Ecology and Evolution. 2009; 24(9): 467-471. doi: 10.1016/j.tree. 2009.03.017.

[13] Stevens M, Vitos M, Altenbuchner J, Conquest G, Lewis J, Haklay M. Taking participatory citizen science to extremes. IEEE Pervasive Computing. 2014; 13(2): 20-29. doi: 10.1109/ MPRV.2014.37.

[14] Shirk JL, Ballard HL, Wilderman CC, Phillips T, Wiggins A, Jordan R, McCallie E, Minarchek M, Lewenstein BV, Krasny ME, Bonney R. Public participation in scientific research: a framework for deliberate design. Ecology and Society. 2012; 17(2): 29. doi: 10.5751/ES-04705-170229.

[15] Skarlatidou A, Suškevičs M, Göbel C, Pruse B, Tauginiene L, Mascarenhas A, Mazzonetto M, Sheppard A, Barrett J, Haklay M, Baruch A, Moraitopoulou EA, Austen K, Baiz I, Berditchevskaia A, Berenyi E, Hoyte S, Kleijssen L, Kragh G, Legris M, Mansilla-Sanchez A, Nold C, Vitos M, Wyszomirski $\mathrm{P}$. The value of stakeholder mapping to enhance cocreation in citizen science initiatives. Citizen Science: Theory and Practice. 2019; 4(1): 24. doi: 10.5334/cstp.226.

[16] Bonney R, Phillips TB, Ballard HL, Enck JW. Can citizen science enhance public understanding of science? Public Understanding of Science. 2015; 25(1): 2-16. doi: 10.1177/0963 662515607406

[17] Devictor V, Whittaker RJ, Beltrame C. Beyond scarcity: citizen science programmes as useful tools for conservation biogeography. Diversity and Distributions. 2010; 16(3): 354-362. doi: 10.1111/j.1472-4642.2009.00615.x

[18] Anderson L, Wilk J, Graham LP, Wikner J, Mokwatlo S, Petja B. Local early warning systems for drought: could they add value to the nationally disseminated seasonal climate forecasts? Weather and Climate Extremes. 2020; 28: 100241. doi: 10.1016/j.wace.2019.100241.

[19] Mugi-Ngenga EW, Mucheru-Muna MW, Mugwe JN, Ngetich FK, Mairura FS, Mugendi DN. Household's socio-economic factors influencing the level of adaptation to climate variability in the dry zones of Eastern Kenya. J Rural Studies. 2016; 43 : 49-60. doi: 10.1016/j.jrurstud.2015.11.004.

[20] Lane SN, Odoni N, Landström C, Whatmore SJ, Ward N, Bradley S. Doing flood risk science differently: an experiment in radical scientific method. Trans Inst Br Geogr. 2011; 36: 15-36. doi: 10.1111/j.1475-5661.2010.00410.x.

[21] Fritz S, See L, Carlson T, Haklay M, Oliver JL, et al. Citizen science and the united nations sustainable development goals. Nature Sustainability. 2019; 2: 922-930. doi: 10.1038/s41893019-0390-3.

[22] United Nations Resolution 2015: 70/1. Transforming our world: the 2030 Agenda for Sustainable Development. www. un.org/ga/search/view_doc.asp?symbol=A/RES/70/1\&Lang= E.

[23] MacFeely S, Nastav B. "You say you want a [data] revolution": a proposal to use unofficial statistics for the SDG global indicator framework. Statistical Journal of the IAOS. 2019; 35 : 309-327. doi: 10.3233/SJI-180486.

[24] Bain R, Johnston R, Slaymaker T. Drinking water quality and the SDGs. npj Clean Water. 2020; 3: 37. doi: 10.1038/s41545020-00085-z.

[25] Hsu A, Malik O, Johnson L, Esty DC. Development: mobilize citizens to track sustainability. Nature. 2014; 508: 33-35

[26] Fraisl D, Campbell J, See L, When U, Wardlaw J, Gold M, Moorthy I, Arias R, Piera J, Oliver JJ, Maso J, Penker M, Fritz S. Mapping citizen science contributions to the UN sustainable development goals. Sustainability Science. 2020; 15: 17351751. doi: 10.1007/s11625-020-00833-7.
[27] Quinlivan L, Chapman DV, Sullivan T. Validating citizen science monitoring of ambient water quality for the united nations sustainable development goals. Science of the Total Environment. 2020; 699: 134255. doi: 10.1016/j.scitotenv.2019.1342 55.

[28] Hadj-Hammou J, Loiselle S, Ophof D, Thornhill I. Getting the full picture: assessing the complementarity of citizen science and agency monitoring data. PLoS One. 2017; 12(12): 1-18. doi: 10.1371/journal.pone.0188507.

[29] Cunha DGF, Magri RAF, Tromboni F, Ranieri VEL, Fendrich AN, Campanhao LMB, Riveros EV, Velazquez JA. Landscape patterns influence nutrient concentrations in aquatic systems: citizen science data from Brazil and Mexico. Freshwater Science. 2019: 38(2). doi: 10.1086/703396.

[30] Sepulcre-Canto G, Horison S, Singleton A, Carrao H, Vogt J. Development of a combined drought indicator to detect agricultural drought in europe. Nat. Hazards Earth Syst. Sci. 2012; 12: 3519-3531. doi: 10.5194/nhess-12-3519-2012.

[31] Hunter J, Alabri A, van Ingen C. Assessing the quality and trustworthiness of citizen science data. Concurrency Computat: Pract. Exper. 2013; 25: 454-466. doi: 10.1002/cpe.2923.

[32] Callaghan CT, Rowley JJL, Cornwell WK, Poore AGB, Major RE. Improving big citizen science data: moving beyond haphazard sampling. PLoS Biol. 2019; 17(6): e3000357. doi: 10.1371/journal.pbio.3000357.

[33] Abbott BW, Moatar F, Gauthier O, Fovet O, Antoine V, Ragueneau $\mathrm{O}$. Trends and seasonality of river nutrients in agricultural catchments: 18 years of weekly citizen science in France. Science of the Total Environment. 2018; 624: 845-858.

[34] Jollymore A, Haines MJ, Satterfield T, Johnson MS. Citizen science for water quality monitoring: data implications of citizen perspectives. Journal of Environmental Management. 2017; 200: 456-467. doi: 10.1016/j.jenvman.2017.05.083.

[35] Bird TJ, Bates AE, Lefcheck JS, Hill NA, Thomson RJ, Edgar GJ, Stuart-Smith RD, Wotherspoon S, Krkosek M, StuartSmith JF, Pecl GT, Barrett N, Frusher S. Statistical solutions for error and bias in global citizen science datasets. Biological Conservation. 2014; 173: 144-154. doi: 10.1016/j.biocon. 2013.07.037.

[36] Walker D, Forsythe N, Parkin G, Gowing J. Filling the observational void: scientific value and quantitative validation of hydrometeorological data from a community-based monitoring programme. Journal of Hydrology. 2016; 538: 713e725. doi: 10.1016/j.jhydrol.2016.04.062.

[37] Brönmark C, Hansson LA. Environmental issues in lakes and ponds: current state and perspectives. Environmental Conservation. 2002; 29(3): 290-306. doi: 10.1017/S0376892902000 218.

[38] Chislock MF, Doster E, Zitomer RA, Wilson AE. Eutrophication: causes, consequences, and controls in aquatic ecosystems. Nature Education Knowledge. 2013; 4(4): 10.

[39] Directive 2000/60/EC of the European Parliament Establishing a framework for community action in the field of water policy. Official Journal of the European Communities, 2000. https:// eur-lex.europa.eu/legal-content/EN/TXT/?uri=celex\%3A3200 OL0060.

[40] Kallis G, Nijkamp P. Evolution of EU water policy: a critical assessment and a hopeful perspective. Zeitschrift Für Umweltpolitik Und Umweltrecht. 2000; 3: 301-335. https://research. vu.nl/en/publications/evolution-of-eu-water-policy-a-criticalassessment-and-a-hopeful-2.

[41] European Commission Directive 91/271/EEC of 1991 concerning urban waste-water treatment. https://eur-lex.europa.eu/ legalcontent/EN/TXT/?uri=CELEX\%3A31991L0271. 
[42] European Commission Directive 91/676/EEC of 1991 concerning the protection of waters against pollution caused by nitrates from agricultural sources. https://eur-lex.europa.eu/ legal-content/EN/TXT/?qid=1561542776070\&uri=CELEX:01 991L0676-20081211.

[43] Ollivier G. An analytical understanding of the Water Framework Directive. Questioning its potential to enable sustainable management of water. Case study monograph 9. SLIM (Social Learning for the Integrated Management and Sustainable Use of Water at Catchment Scale). EVKI-CT-2000-00064-SLIM 2004. http://agris.fao.org/agris-search/search.do?recordID=FR 2016216873.

[44] European Environment Agency. Nutrients in freshwater in Europe, 2015. https://www.eea.europa.eu/data-and-maps/indi cators/nutrients-in-freshwater/nutrients-in-freshwater-assess ment-published.

[45] Administration de la gestion de l'eau. Umsetzung der EG-Wasserrahmenrichtlinie: Bewirtschaftungsplan für da Großherzogtum Luxemburg. Ministry of the Interior, 2009.

[46] Eurostat. Agri-environmental indicator - nitrate pollution of water, 2012. ec.europa.eu/eurostat/statistics-explained/index. php/Archive:Agri-environmental_indicator_-_nitrate_pollu tion_of_water.

[47] European Commission. Common Implementation Strategy for the Water Framework Directive 2000/60/EC. Guidance Document No. 8 on Public Participation in Relation to the Water Framework Directive. https://circabc.europa.eu/sd/a/0fc804ff5fe6-4874-8e0d-de3e47637a63/Guidance\%20No\%208\%20\%20Public\%20participation\%20\%28WG\%202.9\%29.pdf.

[48] Mostert E. Public participation and the European Water Framework Directive. A framework for Analysis: Vol. EVK1-CT2002-00120 (HarmoniCOP project - Harmonising Collaborative Planning). Delft University of Technology, 2003.

[49] United Nations Economic Commission for Europe Convention on access to information, public participation in decisionmaking and access to justice in environmental matters, 1998. https://treaties.un.org/Pages/ViewDetails.aspx?src=IND\& mtdsg_no=XXVII-13\&chapter $=27$.
[50] Carr G. Stakeholder and public participation in river basin management - an introduction. Wiley Interdisciplinary Reviews: Water. 2015; 2(4): 393-405. doi: 10.gftd2c.

[51] Jager NW, Challies E, Kochskämper E, Newig J, Benson D, et al. Transforming european water governance? Participation and river basin management under the EU water framework directive in 13 member states. Water. 2016; 8(4): 156. doi: 10 . f3rrf9.

[52] Mostert E, Pahl-Wostl C, Rees Y, Searle B, Tàbara D, Tippett J. Social learning in european river-basin management: barriers and fostering mechanisms from 10 river basins. Ecology and Society. 2007; 12(1): 19.

[53] Pahl-Wostl C. Water Governance in the Face of Global Change. Springer International Publishing. 2015. doi: 10.1007/978-3319-21855-7.

[54] natur\&ëmwelt a.s.b.l. - Über uns. https://www.naturemwelt. lu/de/ueber-uns.

[55] Earthwatch FreshWater Watch. https://earthwatch.org.uk/getinvolved/freshwater-watch.

[56] Castilla EP, Cunha DGF, Lee FWF, Loiselle S, Ho KC, Hall C. Quantification of phytoplankton bloom dynamics by citizen scientists in urban and periurban environments. Environmental Monitoring and Assessment. 2015; 187: 690. doi: 10.1007/s10661-015-4912-9.

[57] Loiselle S, Cunha DGF, Shupe S, Valiente E, Rocha L, Heasley E, Belmont PP, Baruch A. Micro and macroscale drivers of nutrient concentrations in urban streams in South, Central and North America. PLoS One. 2016; 11(9): e0162684. doi: 10.1371/journal.pone.0162684.

[58] August TA, West SE, Robson H, Lyon J, Huddart J, Velasquez F, Thornhill I. Citizen meets social science: predicting volunteer involvement in a global freshwater monitoring experiment. Freshwater Science. 2019; 38(2): 321-31. doi: $10.1086 / 703416$.

[59] Madema W, Wals A, Adamowski J. Multi-loop social learning for sustainable land and water governance: towards a research agenda on the potential of virtual learning platforms. NJAS Wageningen Journal of Life Sciences. 2014; 69: 23-38 